\title{
Urban Civility: Train Commuters' Queueing Behaviour in Jakarta
}

\author{
Maria Astrid Susanti ${ }^{1}$, Zulfikar Ilham Mirza ${ }^{2}$, Her Daneswara Prajna Mahesa ${ }^{3}$, Reandra \\ Fasdityo Poerba ${ }^{4}$, Aldi Riawan Kurningsih ${ }^{5}$, Fairuziana ${ }^{6}$ \\ Faculty of Psychology, Universitas Indonesia, Depok, Indonesia \\ *E-mail: maria.astrid51@ui.ac.id
}

\begin{abstract}
Queueing is an act of civility that exists in all parts of the world, particularly in the urban environment. This study looks at the queueing behaviour of commuter line passengers who are purchasing a ticket from a ticket booth in Manggarai Train Station, Jakarta, Indonesia. The behaviour indicated whether commuters in Jakarta show civil or uncivil manners. 363 participants took place in this naturalistic observation with four observers collecting the data. Results suggest that most commuters in Jakarta show civil behaviour with only 25 people (6.89\%) showing uncivil behaviour according to the queueing activity. The study findings recommended some strategies to reduce the number of people who do not queue which would further contribute to the urban behaviour study in psychology.
\end{abstract}

Keywords: queueing, civility, urban, public transportation, commuter line

\section{Introduction}

Jakarta has the highest urban density in Indonesia with a population of $10,075,310$ people (Department of Population and Civil Registration of DKI Jakarta Province, 2016). The increasing number of motorised vehicles results in highly congested traffic. Because of this, many of its citizens prefer to choose public transportation to commute from place to place, as it is much cheaper and faster compared to using private transportation. As Jakarta is considered as a fast-paced city, the citizens are mostly in a rush, and thus quick methods of transportation are much needed ("GaWC - The World According to GaWC 2017", 2017). One such type of transportation is the railway.

As Jakarta is the capital and the largest city in Indonesia, it has the most advanced local railway system in the country. The system is called the "Kereta Rel Listrik - Commuter Line" or KRL commuter line for short. Furthermore, KRL has been rated as "Jakarta's best mode of transportation in 2016" (Hakim, 2017). KAI has also claimed on their website that their vehicle is the "Best Urban Choice Transportation". In average, the commuter line company serves 850,000 people each day in 72 stations (PT. KAI). This situation demands the passenger to act civil such as queuing.
Queueing is a vital behaviour to study in Jakarta because the city has to maintain between the dense population with the advancement of plentiful public transportations. Hence, queueing behaviour when purchasing ticket is needed in order to make the public transportations run effectively. However, there are still some people that do uncivil behavior in regard to queueing, such as cutting the line without feeling any guilt even though a queue line is already made, and this problematic behavior becomes the research focus, as this shows incivility and disrespectfulness because it is considered as a selfish behavior where "me-first" ego is not repressed but projected.

According to this situation, the ticket booth in the train station is the best option if the researchers wish to find out the general urban behaviour of people in and around Jakarta. The hypothesis of this study is there are some people who perform uncivil behaviour of not queuing in the KRL ticket booth station. In the Jakarta's public transportations, queueing behaviour in purchasing a ticket in the train station is already well practised. However, as most of the people are such in a rush, there would still be some people that do the uncivil behaviour in queueing such as cutting the line in order to save their time. Because of the lack of awareness of such a small civil behaviour, this has led a slowdown in how the country develops both physically and in terms of its people (Munir, n.d.). 
Furthermore, a lack of proper queueing management system can increase crowd-inflicted aggression and can harm others who are in the same queue (Townsley, \& Grimshaw, 2013). Therefore, it is vital that this study takes place to observe the queueing behaviour of Jakarta citizens.

The aim of this study is to describe the attitude of people who are queueing to purchase a ticket in the train station and use the commuter train as their daily transportation and spend their daily activities in Jakarta. This study used descriptive study with naturalistic observation method. Another aim of this project is to raise awareness regarding the importance of queueing because it is considered as an act of civility. Therefore, the research question of this study is "How do people in Jakarta behave in terms of queueing at the train station's ticket booth?".

\section{Literature Review}

\subsection{Civility}

Civility is defined simply as decency (Peck, 2002; In Wilkins et al., 2010). It includes characteristics like courtesy, politeness, consideration gentility, and respect, as well as dispositions like caring, looking beyond selfishness, or seeking ways to help those in need (Hinckley, 2000; In Wilkins et al., 2010). As simple as giving a seat to an older person on public transportation or helping a person whose car stalled is an example of civility. Human as a social being, need to held civility characteristics to prevent us from having a chaotic society where no one has respects and courtesy to each other that violence, crime, and war could happen anytime. On the other hand, incivility refers to behaviours that disrupt social harmony or disregards the humanity of a person (Hinckley, 2000 in Wilkins et al., 2010). Although uncivil behaviours are thought to appear as ambiguous initially, they can lead to more aggressive and violent actions (Conerly-Glenn, 2015). Incivility includes but is not limited to horizontal/lateral violence, bullying and disruptive behaviour, and workplace aggression and disruptive behaviours (Clark \& Carnosso, 2008; Feblinger, 2008; Hutton \& Gates, 2008; In Conerly-Glenn, 2015), even ignoring to act civilly, may be defined as uncivil. Uncivil behaviours often emit negative energy found in rudeness, disrespect, discourteousness, and disregard for individuals.
Furthermore, incivility found in metropolitan cities are often caused by people experiencing workplace incivilities such as bullying and over-expectations from subordinates (Zhou, Yan, Che, \& Meier, 2015). The study shows that the experience of workplace incivility is carried further in public places meaning that those who have experienced workplace incivility will express public incivility as a defence mechanism. There are still individual differences at play as the same study mentions that a person's emotional stability, external locus of control and attribution bias affect how often they will act in public.

\subsection{Queueing}

Queueing, in general, refers to an action when a person waits before receiving services that they wish. It sometimes can be perceived negatively by some people making it a negative stimulus to some people who can make them feel more agitated than usual (Munichor, \& Rafaeli, 2007). The negative perception of queueing in some people is of utmost importance as this mild inconvenience is often found to be the result of some people becoming more aggressive than normal, thus leading to incivility (Clemmer \& Schneider, 1989; In Munichor \& Rafaeli, 2007). In this context of buying a ticket in the train station, the right explanation of a queuing process consists in customers arriving at a servicing facility, then lining up if all servers are busy, eventually receiving service, and finally departing from the facility (Olawepo, 2014).

Societies, which facilitate the development of queues show respect and civility (Boyd, 2006; In Wexler, 2015) for those adhering to the group norms. The social system of the queue involves repressing the "me-first" ego of the individual and calling upon the leaderless queue to maintain order (Helweg-Larsen and LoMonaco, 2008; In Wexler 2015). Sociology of the waiting line highlights the civility of an emergent form of orderliness. The act of queueing itself has seen very little academic research contributed towards it. One research found that the reason why people are very resistant to others cutting the line is because "they fear to lose their queue position, thereby encountering unexpected costs, such as additional waiting time, or, in the case of a limited resource, the potential loss of the good or service" (Schmitt, Dubé \& Leclerc, 1992). Other studies noted that queueing is seen as a localised social system where intrusions are seen as aggressive in only specific parts of the queue and not the whole queue in general (Milgram, Liberty, Toledo, \& Wackenhut, 1986). 


\section{Methods}

Sample. The participants that took place in this study were people as passengers who were queueing to buy a train ticket in the ticket booth. To obtain knowledge about queueing behaviour that represents civility in Jakarta society, we chose Manggarai Train Station as the observation place because this is one of the biggest and busiest train stations in Jakarta with 10 rails coming and going to different regions of Jakarta. The station also became an intersection station where commuters usually depart before they change lanes to another train stations. Statistics by PT.KAI stated that approximately 800 thousand passengers are using this public transportation each day, and having Manggarai Train Station as the central intersection station with trains originating from several termini such as Tangerang, Maja, Tanjung Priok, Bekasi, and Bogor. It can be said that this people-who are of diverse backgrounds-will cross stop and exchange railways in this station. Due to this fact, this created a hectic atmosphere, thus creating the effect of "rush" in the passengers. Prolonged exposure to the feeling of "rush" might generate uncivil queueing behaviour. Therefore, Manggarai Train Station was the best representation of the queueing behaviour in Jakarta.

Citizens of Jakarta can be seen queueing for a topup of their COMMET (Commuter Electronic Ticketing) in the Commuter Vending Machine (CVIM) that operate by themselves and the manual ticket booth that runs by the train station's officers. In this observational study, the subject of the observation would be people who are enacting the behaviour of queueing for a top-up of their COMMET card. Time sampling is used to find participants in this study.

Research Design. Naturalistic observation will be used in this study.

Instrument and Measurement. The researchers set up a behavioural checklist to be filled according to the behaviour presence or not present then identify the behaviour indicated in the form. This checklist was based on the researchers' prior knowledge about the observed behaviour. There were four behavioural criteria that we observe; standing in line, cutting in line, pushing and creating a new line.
Each of these criteria indicated uncivil behaviours. If an observed ticket buyer showed none of these criteria, then it could be concluded that the observed buyer is exhibiting civil behaviour.

Table 1.

Behaviour Checklist

Behaviour Description Present Not Present

\begin{tabular}{ll}
$\begin{array}{l}\text { Standing in } \\
\text { the line }\end{array}$ & $\begin{array}{l}\text { But does not start at } \\
\text { the end or following the queue }\end{array}$ \\
\hline $\begin{array}{l}\text { Cutting the } \\
\text { Line }\end{array}$ & $\begin{array}{l}\text { Passengers enter the train by going } \\
\text { straight through the door rather than } \\
\text { waiting behind the queue. The same } \\
\text { behaviour applies in the ticketing } \\
\text { booth }\end{array}$ \\
\hline Pushing & Disturbing the line and other people \\
\hline $\begin{array}{l}\text { Creating } \\
\text { new line } \\
\text { beside the } \\
\text { designated } \\
\text { or existing } \\
\text { line }\end{array}$ \\
\hline
\end{tabular}

Procedure. In this study, we believe that variable manipulation and creating situations are not necessary as it already exists in the city that the researchers wish to observe in. In the observation, there are three group members who engaged in the observation of the quantity of people who queue and two observers who will observe in any evidence of uncivil behaviour in a given period of one hour from 17:40 - 18:40 GMT +7 which is considered the peak of rush hour in Jakarta. Two group members were assigned to observe uncivil behaviour that might occur during the given period using the behaviour checklist. Inter-observer reliability is maintained by having two observers seeing any occurrence of uncivil behaviour such as standing in line, cutting the line, pushing and creating a new line adjacent to the designated line in the behaviour checklist. One member was assigned to observe the number of people buying tickets for two lines; both being electronic ticket booths lines, and the other member to observe another two lines; one being the electronic ticket booth line and the other being the manual ticket booth line. This is done through a tally system in which one person who shows at least one indicator from the behaviour checklist will be counted as one point. As of the positions of the observers during the observational period, members of the group positioned themselves several meters 
behind the lines so that each one of them may observe their target behaviour yet not disturbing the people who queue.

\section{Results}

In the time when the researcher observed Manggarai Train Station queueing line of ticket booths, there is 4 active queueing line that consists of three electronic booths and one manual ticket booth that is run by the train station's officer.

With a time span of one hour, the team observed 104 people ( 34 on the leftmost \& 70 on the centre booth) passing and buying tickets for the leftmost and centre electronic booth combined. In total, we observed 11 people with an uncivil queueing behaviour. For instance, 9 out of 11 people who are uncivil, show the behaviour of "standing in the line" where they queue but does not start from the original queue and creates a new line for the same ticket booth.

The next most common seen behaviour among the 11 people is "creating a new line beside the designated line" with 5 out of 11 shown. The difference between "standing in line" and "creating a new line beside the designated line" is that in the former, a new line is made that joins the already made line. The latter show behaviour where there is an entirely new line that ends in the ticketing booth. The next most common behaviour shown is explicitly cutting the line where 5 out of 11 were observed. Out of four behaviours that were in the checklist, there was no pushing observed, where 0 out of 11 were observed. In total, the results show 11 out of 104 queuers or $11.6 \%$ of queuers show uncivil behaviour.

The manual booth has seen just as many passengers purchasing their tickets when compared to the CVIM. The manual booth has seen 259 people standing in line to make a purchase compared to 115 in the rightmost C-VIM. In total, the manual booth and the rightmost C-VIM has produced 14 uncivil behaviours. Out of 14 uncivil behaviours, the most common type of behaviour shown is "cutting" in line with 11 cases. "Standing in line" is the second most common shown uncivil behaviour with a total of 9 cases. Similarly, there are no shown cases of "pushing" in this section of the queue. In total, 14 people who queue out of 259 or $5.4 \%$ of people who queue show uncivil behaviour.

\section{Discussion}

From the results, the number of total people who queue outnumbered the number of uncivil queuers, which is 25 out of 478 or $5.23 \%$ of the total people who queue. This number is suitable for the hypothesis, that is, queueing behaviour is already well practised. However, as most of the people are such in a rush, there would still be some people that do the uncivil behaviour in queueing to save their time. Although the percentage might be low in value, these uncivil people who queue give a significant impact on the queue with their behaviour. The behaviour of queue jumping is easily modelled by other people who queue as the reaction from the victims is what made the behaviour seemed acceptable as they will just stand still and do nothing which gives an insight that queue jumping as acceptable behaviour. It is related to Bandura's (1978) learning theory of observational learning through modelling and vicarious reinforcement, where a person imitates the behaviour of someone who has been reinforced for that behaviour. The other potential queue jumpers or even the people who queue itself will be reinforced to do the behaviour as they will only receive a reward because none will complain about what they will do. Thus, it is likely possible that the percentage will increase in time if no action is taken regarding this matter. Also, Manggarai Train Station is the biggest train station available that acts as the central intersection for train passengers that came from many regions of Jakarta and is more technologically developed than any other train station which the customers should be civilised. Furthermore, the observation conducted has also identified the PT. KAI's effort to organise the queue line by providing poles that are connected with straps to divide and show where the line should be queued. This fact is what made such low percentage of queue jumpers from the observation are considered high and gave a significant impact and reflection of citizens.

Queueing is an act of respect of human rights, where everyone waits for their turn to get what they wish for and according to Helweg-Larsen and LoMonaco (2008) it involves repressing the "mefirst" ego of the individual and calling upon the leaderless queue to maintain order. It can be seen in the remaining $94.77 \%$ of people who queue who adhere to the rule of queueing. On the other hand, the behaviour of queue jumping is considered as uncivil because it disrupts social harmony by disregarding the humanity of a person and shows disrespectfulness toward human rights as shown by the remaining 5.23\%. Although such an act might appear as simple, this behaviour should be given more attention because according to Conerly-Glenn 
(2015) uncivil behaviour could result in a chaotic situation when the victims would be aggressive and might lead to violent actions. Queue jumping according to Schmitt et al. (1992) could lead to unexpected costs, which means the victims will experience an additional waiting time or in some cases, potential loss of goods or services could also happen. Thus, the behaviour of queue jumping could lead to more complications. Although the observation did not find any reactions from the victims, other future victims might give reactions that mostly will turn out aggressive and civility which will be disregarded when this kind of situation occurred (Munichor \& Rafaeli, 2007).

There are several limitations that can be improved in this study. The first limitation is that the behaviour checklist is based only on common knowledge and the researchers' prior observations only. There is almost no theoretical background regarding the target observed behaviour. Therefore it is suggested that further research should be done before attempting this study.

Furthermore, during the observation, the researchers did not count the mean of queues within each line and how long they spent queueing. Due to this, it cannot be concretely determined how incivility negatively impacts Jakarta's commuters regarding time spent and comfort. In the future, it is suggested that the mean of queues within a point of time is counted within each line.

The next limitation is the lack of observers and the limited time of observation. The lack of observers has limited the accuracy of data obtained due to the observer being overwhelmed by the number of queues. Also, one hour of observation in only one day is insufficient to generate enough data to generalise to the population of Jakarta. In the future, it is suggested that there are more observers conducting the observation and extend the observation period to more than one day.

\section{Conclusion}

Conclusion. In conclusion, many efforts are needed to improve the civility regarding the queueing behaviour in Jakarta's public transportation, specifically, train station. This intervention can help and create better-civilized behaviour that finally will improve the psychological welfare of the Jakarta's citizen in using the train station and creating a more civil population.
Suggestions for the public. The researchers would like to make some suggestion regarding the uncivil behaviour of queue jumping regarding queueing in Manggarai Train Station or other train station operated by PT KAI in general. The intervention that the researchers recommend is the creation of new laws regarding queue. Firstly, PT KAI can use the operant conditioning theories in making the new regulations for the passengers of the train, such as the use of reinforcements and punishments. PT KAI may give positive punishments regarding the act of those passengers who cut the line, such as command them to start queue again from behind the line which is a form of positive and negative punishment because the reward of gaining a shortcut of time is taken away from them, and the aversive stimuli is added, i.e. have to wait longer. The use of negative punishment could also be done, for instance, by giving a fine with a significant amount that is enough to make the queue jumpers perceive it as an aversive stimulus. Assigned security that focuses on observing the queue line will help to detect queue jumpers which they will be the one who will give further actions according to the punishments that the perpetrators will receive.

To further support this, a proper law which would reinforce the victims to take actions when they got cut in queueing, will help the extinction of queue jumping behaviour. As have been stated in the discussion, the act of allowing others to cut the line should also be removed, as it serves as a reinforcement for such uncivil behaviour. Moreover, positive reinforcement can be used, such that every time a victim reports the action to the assigned security of queue line, the victims will get a reward which could be given an amount of money or to give more effectiveness to the extinction of queue jumping, the victims who reported would be given the opportunity to skip the queue line and be the one who will be the next person who will be given the service they wished for. However, to be able to have or attain proof to support the accusation, there should be an apparatus help gather the claims objectively despite how the victim reports. The researcher suggests that CCTV should be put in place where a member of the PT KAI is responsible for. The member then acts as a liaison from the victims to the higher authority which his or her job is to help search the appointed time of the event of uncivil behaviour recorded in the CCTV which would then act as objective proof of the claim. 


\section{References}

Assmann, A. (2013). Civilizing societies: Recognition and respect in a global world. New Literary History, 44(1), 69-91,199.

Bandura, A. (1978). Social learning theory of aggression. Journal of communication, 28(3), 12-29.

Bejan, T. M. (2013). Mere civility: Toleration and its limits in early modern England and America (Order No. 3572029). Available from ProQuest Dissertations \& Theses Global. (1490792503)

Clemmer, E. C., \& Schneider, B. (1989). Toward understanding and controlling customer dissatisfaction with waiting. Cambridge, MA: Marketing Science Institute.

Conerly-Glenn, Y. (2015). Influences of civility on learning (Order No. 3687628). Available from ProQuest Dissertations \& Theses Global. (1668379775).

Dinas Kependudukan dan Pencatatan Sipil Provinsi DKI Jakarta. (2016). Data Penduduk DKI Jakarta Berdasarkan Kelamin Dan Kewarganegaraan. Jakarta: Dinas Kependudukan dan Pencatatan Sipil.

GaWC- The World According to GaWC 2017. (2017). Lboro.ac.uk. Retrieved 14 May 2017, from http://www.lboro.ac.uk/gawc/world2016t.html

Gravetter, F., \& Forzano, L. (2011). Research methods for the behavioral sciences (1st ed.). Belmont, Calif.: Wadsworth.

Hakim, A. (2017). Home. KRL. Retrieved 15 May 2017, from http://www.krl.co.id/\#_m_infoterkini

Milgram, S., Liberty, H., Toledo, R., \& Wackenhut, J. (1986). Response to intrusion into waiting lines. Journal Of Personality And Social Psychology: Interpersonal Relations And Group Processes, 51(4), 683-689.

Munichor, N., \& Rafaeli, A. (2007). Numbers or apologies? Customer reactions to telephone waiting time fillers. Journal Of Applied Psychology, 92(2), 511-518. http://dx.doi.org/10.1037/0021-9010.92.2.511
Munir, M. Membangun Karakter Melalui Budaya Mengantri. Uinsby.ac.id. Retrieved 14 April 2017, from http://www.uinsby.ac.id/kolom/id/79/membangunkarakter-melalui-budaya-mengantri

Olawepo, G. T. (2014). Analysis of M/M/1/3 as a Means of Decision Making In Banking Industry. International Journal of Advanced Research in Computer Science, 5(3), 1-3.

PT. KAI, Sekilas PT. KAI Commuter Jabodetabek. Retrieved 15 August 2017, from http://www.krl.co.id/

Schmitt, B., Dubé, L., \& Leclerc, F. (1992). Intrusions into waiting lines: Does the queue constitute a social system?. Journal Of Personality And Social Psychology, 63(5), 806-815. http://dx.doi.org/10.1037/0022-3514.63.5.806

Townsley, M. \& Grimshaw, R. 2013, "The consequences of queueing: Crowding, situational features and aggression in entertainment precincts", Crime Prevention and Community Safety, vol. 15, no. 1, pp. 23-47.

Wexler, M. N. (2015). Re-thinking queue culture: The commodification of thick time.The International Journal of Sociology and Social Policy, 35(3), 165-181.6

Wilkins, K., Caldarella, P., Crook-Lyon, R., \& Young, K. R. (2011). Implications of civility for children and adolescents: A review of the literature. Issues in Religion and Psychotherapy, 33, 37-45

Zhou, Z., Yan, Y., Che, X., \& Meier, L. (2015). Effect of workplace incivility on end-of-work negative affect: Examining individual and organizational moderators in a daily diary study. Journal Of Occupational Health Psychology, 20(1), 117-130. http://dx.doi.org/10.1037/a0038167 